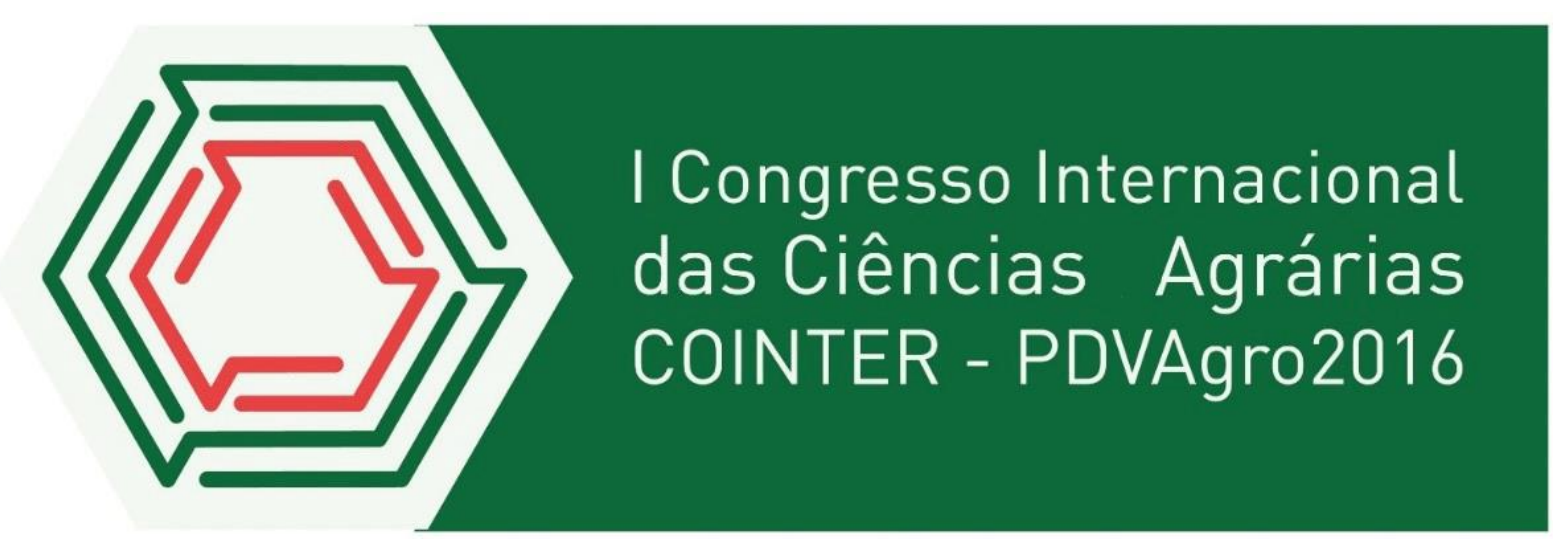

\title{
SISTEMA DE PRODUÇÃO AGROECOLÓGICO EM UMA COMUNIDADE RURAL DO SEMIÁRIDO NORDESTINO
}

\author{
Apresentação: Comunicação Oral
}

\begin{abstract}
Sebastiana Joelma de Azevedo Santos ${ }^{1}$; Josefa Patrícia Balduino Nicolau ${ }^{2}$; Cynthia de Lima Campos $^{3}$
\end{abstract}

\begin{abstract}
Resumo
A agroecologia tem a capacidade de afirmar o potencial transformador, com a idéia de que a mudança é um processo evolutivo e crescente respeitando os conhecimentos empíricos. Este estudo teve como objetivo observar e analisar os sistemas de cultivo e produção animal agroecológica, bem como as técnicas utilizadas para o manejo dos recursos naturais aplicadas na comunidade rural Logradouro, analisando-as sob a perspectiva da sustentabilidade econômica, social e ambiental. O referente trabalho foi realizado no município de Baraúna, Estado da Paraíba, no Sítio Logradouro, na unidade familiar produtiva, no mês de julho de 2016. Em relação aos procedimentos metodológicos efetuados para a realização dessa pesquisa, além das diversas leituras que tratam sobre agroecologia, saberes tradicionais e tecnologias sociais em regiões semiáridas, estes foram iniciados com uma visita à comunidade através de um trabalho de campo, afim de observar e analisar os sistemas de cultivo e produção agroecológica, bem como as técnicas utilizadas para o manejo nessa comunidade. Paralela a primeira ação destacada, com o objetivo de obter dados, informações e históricos locais com os moradores da comunidade, utilizamos entrevistas livres e abertas (semiestruturadas), conversas informais e observações diretas. As informações obtidas foram analisadas de forma comparativa e descritiva, registrando-se os momentos da pesquisa com câmera fotográfica. Observei que dentre as plantas cultivadas no sistema de produção agroecológico da comunidade Logradouro, município de Baraúna, houve uma preferência pelo cultivo de hortaliças, frutíferas e plantas medicinais. Como também as culturas anuais de milho e feijão no período das águas. As hortaliças representam para a família uma segurança alimentar sendo comercializado o seu excedente. Constatou-se uma grande variedade de espécies de plantas cultivadas, sendo a alface (Lactuca sativa) e o tomate (Solanum lycopersicum) as plantas mais cultivadas. De acordo com a visita na área do sistema agroecológico da família foi possível mapear 21 espécies vegetais. Conclui-se com este estudo de caso que a comunidade rural Logradouro atende aos parâmetros agroecológicos. As atividades alternativas de sistemas produtivos praticadas para a subsistência familiar está voltado para a produção de hortaliças, plantas medicinais, frutíferas, avicultura e apicultura, com base no desenvolvimento rural sustentável.
\end{abstract}

1 Pós-graduação em Gestão dos Recursos Ambientais do Semiárido, IFPB, joelmaifpbpicuiy@gmail.com

2 Pós-graduação em Gestão dos Recursos Ambientais do Semiárido, IFPB,

patrícia.balduino@hotmail.com

3 Professora do Curso de Agroecologia, IFPB, cynthiazinha1@gmail.com 
Palavras-Chave: Agroecologia, semiaridez, sistema produtivo, sustentabilidade.

Introdução

A crise ecológica que vem sendo exposto à sociedade nestes últimos anos, não poderia ser desassociada da internacionalização da agricultura industrializada como forma hegemônica de manejo dos recursos naturais (MOREIRA e CARMO, 2004).

Em relação à agricultura mundial, numa escala histórica mais recente, podemos mencionar dois modelos distintos. O primeiro destes, conhecido como Revolução Verde, surgiu na década de 1970, consistindo no aumento de produção e produtividade agrícola, assentando-se no uso intensivo de variedades de alto rendimento melhoradas geneticamente, adubos de síntese química, agrotóxicos, irrigação e mecanização, gerando o que passou a ser conhecido como "pacote tecnológico" (MÜLLER et al., 2001).

No entanto, estas técnicas de aumento da produtividade agrícola acabaram resultando em graves consequiências sócioambientais. Gliessman (2001) aponta alguns destes efeitos degradantes causados pela agricultura convencional insustentável: infertilidade do solo, desperdício e uso exagerado da água, poluição do ambiente, dependência de insumos externos, perda da diversidade genética e do controle local sobre a produção agrícola.

O segundo modelo agrícola que vem ganhando espaço atualmente é a agricultura ecológica, mais conhecida como agroecologia. Este se propõe a construir, nesse tipo de uso do solo, um ecossistema ecologicamente equilibrado ou, conforme define (KUSTER et al., 2008), que agroecologia é trabalhar a agricultura de forma sustentável, ou seja, ecologicamente sustentável, socialmente justa e economicamente viável.

A agroecologia tem a capacidade de afirmar o potencial transformador, com a idéia de que a mudança é um processo evolutivo e crescente respeitando os conhecimentos empíricos. A metodologia aplicada por essa ciência traz alternativas e técnicas viáveis capazes de superar ás divergências encontradas na produção de alimentos pela agricultura convencional. Com base nisso é necessário que haja atitudes corretas para que alcance qualquer êxito em relação ao manejo e conservação dos recursos naturais, como também vise à qualidade de vida das pessoas que consomem os alimentos produzidos.

O Sítio Logradouro, situado na zona rural do município de Baraúna estado da Paraíba é uma propriedade agrícola produtiva, de caráter familiar, que situa-se nos princípios agroecológicos, produz e comercializa hortaliças e produtos oriundos da avicultura e apicultura. Observa-se conscientização do proprietário a aderir a esse modelo de produção, visando melhorias na questão ambiental, no bem estar animal e nas condições de vida das pessoas do campo e as que consomem os alimentos produzidos. O produtor encara alguns 
desafios quanto à mudança de práticas convencionais por práticas alternativas e tecnologias mais sustentáveis.

De forma geral, por possuírem maior poder financeiro, os maiores usuários dos pacotes tecnológicos são proprietários de terra mais capitalizados, enquanto, pela razão inversa, os pequenos produtores são os que mais se utilizam dos saberes tradicionais e, cada vez mais, da agroecologia e das tecnologias sociais, o que vem trazendo, para estes últimos, ganhos não apenas econômicos, mas também sociais e ambientais.

Quanto a difusão e otimização dos saberes tradicionais e tecnologias sociais já existentes, além do desenvolvimento de outras, várias ações têm sido empreendidas, principalmente através das universidades públicas e da participação de Organizações NãoGovernamentais (ONGs) embora, diante do quadro sócio-econômico e ambiental que se mostra no semiárido brasileiro, muito ainda há o que ser feito.

No estado da Paraíba, onde cerca de $90 \%$ do seu território está inserido nos climas semiárido e sub-úmido seco, a situação não é diferente, mesmo que as entidades anteriormente destacadas, dentre outras, venham realizando trabalhos que tentam mudar um pouco essa realidade.

A partir dessas reflexões, o referente trabalho teve como objetivo observar e analisar os sistemas de cultivo e produção animal agroecológica, bem como as técnicas utilizadas para o manejo dos recursos naturais aplicadas na comunidade rural Logradouro, analisando-as sob a perspectiva da sustentabilidade econômica, social e ambiental.

\section{Fundamentação Teórica}

O trabalho com agroecologia vem sendo desenvolvido na região desde os anos de 2008, pelas Organizações Não Governamentais (ONGs), em especial o CEOP (Centro de Educação e Organização Popular) em parceria com a ASA (Articulação no Semiárido Brasileiro) que assessora as famílias da regiões Seridó e Curimataú paraibano. A agroecologia vem sendo compreendida como: um campo de estudos que se pautam no manejo ecológico dos recursos naturais, para através de uma ação social coletiva de caráter participativo, de um enfoque holístico e de uma estratégia sistêmica, reconduzir o curso alterado da coevolução social e ecológica, mediante um controle das forças produtivas que estanquem seletivamente as formas degradantes e expoliadoras da natureza e da sociedade (CAPORAL, 2009).

A ameaça das mudanças climáticas globais para a agricultura tem causado preocupação, uma vez que fatores climáticos indispensáveis para o desenvolvimento dos cultivos agrícolas, como a chuva e a temperatura, serão severamente afetados e certamente 
comprometerão a produção alimentar (NICHOLLS; ALTIERI, 2012). Em zonas semiáridas, os trabalhos com agroecologia vem sendo pautado principalmente em áreas rurais, por essas áreas estarem mais expostas as consequências das mudanças climáticas. A tendência é de haver uma maior frequência e severidade das secas e do calor, condições que podem limitar significativamente o desenvolvimento e o rendimento dos cultivos das famílias agricultoras, fazendo necessárias mudanças no manejo e práticas da produção agrícola (NICHOLLS; ALTIERI, 2012).

Segundo os dois autores, os agricultores familiares seguidos por suas diferentes práticas de manejos agroecológicos podem apresentar uma notável capacidade de resiliência, que muito têm sido prestigiadas no âmbito dos agroecossistemas. Por resiliência entendese: "A capacidade intrínseca de um sistema produtivo em manter sua integridade no decorrer do tempo, sobretudo em relação a pressões externas” (HOLLING, 2007).

A diversidade de alternativas e estratégias de convivência que uma família agricultora é capaz de criar é considerada um elemento central na construção da resiliência de sistemas agroecológicos (BROOKFIELD, 2007). Segundo Altieri e Nicholls (2012), resultados de pesquisas recentes sugerem que muitos agricultores têm se adaptado e, inclusive, se preparado para as mudanças climáticas, minimizando as perdas por meio do emprego de diversas estratégias, entre elas: maior utilização de variedades genéticas locais tolerantes à seca, captação de água da chuva, sistema de produção diversificada, agroflorestas, entre outros. Essas estratégias exibem uma maior estabilidade e menor perda de produtividade durante a seca.

A diversificação dos sistemas produtivos apresenta-se, portanto, como uma estratégia importante para contornar os riscos de perda de produção, além de que, na maioria dos casos, as famílias agricultoras mantêm a diversidade como um mecanismo de segurança para enfrentar a mudança ambiental ou para responder a futuras necessidades sociais e econômicas (ALTIERI; NICHOLLS, 2012). Os sistemas agroecológicos podem garantir uma manutenção de alto nível de biodiversidade, com o emprego de múltiplas espécies e variedades que se combinam em variados arranjos no espaço e no tempo; fator esse que contribui para menor vulnerabilidade aos riscos climáticos, principalmente quando comparados aos sistemas convencionais de agricultura (NICHOLLS; ALTIERI, 2012).

\section{Metodologia}

A área de estudo localiza-se no município de Baraúna, Estado da Paraíba, na mesorregião da Borborema e microrregião do Seridó Oriental Paraibano, com uma população 
de 4.222 habitantes (IBGE, 2012) e caracterizado como de clima semiárido, com verão seco. Apresenta uma área de $50,577 \mathrm{~km}^{2}$ e encontra-se inserida na Bacia Hidrográfica do rio Seridó limita-se com os municípios de Picuí, Cuité, Sossego, Pedra Lavrada e Nova Palmeira com uma altitude média em relação ao nível do mar de 626 metros (AESA 2016).

Figura 1 - Localização da área de estudo. Fonte: Google imagens.

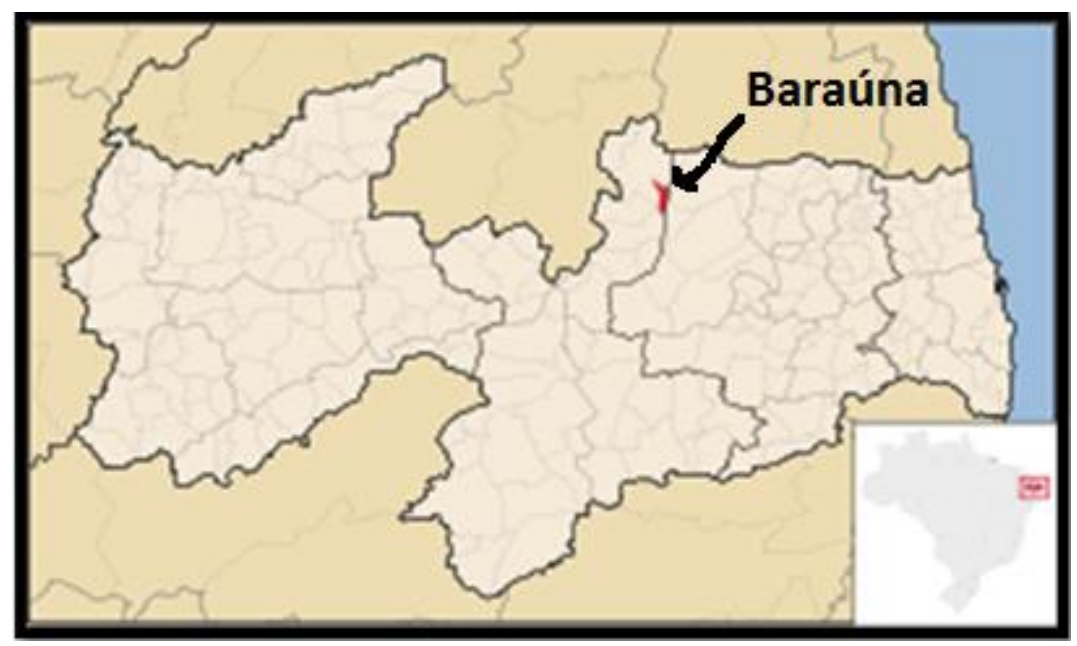

A pesquisa foi conduzida no Sítio Logradouro, na unidade familiar produtiva, no município de Baraúna (aproximadamente $5 \mathrm{Km}$ do centro urbano e $224 \mathrm{Km}$ da capital João Pessoa), Estado da Paraíba, no mês de julho de 2016. Do ponto de vista das características naturais dominantes, essa comunidade encontra-se inserida numa área com chuvas irregulares e torrenciais, variando entre médias de 300 a $800 \mathrm{~mm} /$ ano; vegetação de caatinga; solos rasos (Neossolo Regolítico e Neossolo Litólico) com grande incidência de afloramentos rochosos (CARVALHO, 1992).

Em relação aos procedimentos metodológicos efetuados para a realização dessa pesquisa, além das diversas leituras que tratam sobre agroecologia, saberes tradicionais e tecnologias sociais em regiões semiáridas, estes foram iniciados com uma visita à comunidade através de um trabalho de campo, afim de observar e analisar os sistemas de cultivo e produção agroecológica, bem como as técnicas utilizadas para o manejo nessa comunidade.

Paralela a primeira ação destacada, com o objetivo de obter dados, informações e históricos locais com os moradores da comunidade, utilizamos entrevistas livres e abertas (semi-estruturadas), conversas informais e observações diretas conforme orienta Viertler (2002) . Sendo assim, as perguntas efetuadas aos entrevistados foram estruturadas de forma a não induzir as suas respostas, possibilitando a obtenção de dados qualitativos (TRIVINOS, 1992). 
O estudo de caso seguiu uma orientação científica e descrição do conhecimento, mediante uma estratégia de coleta de informações e conclusão de dados, com vistas à descrição das tecnologias e práticas de caráter agroecológico que são usadas nos sistemas produtivos de hortaliças e criação de animais de pequeno porte, na unidade produtiva familiar Sítio Logradouro. As informações obtidas foram analisadas de forma comparativa e descritiva, registrando-se os momentos da pesquisa com câmera fotográfica.

\section{Resultados e Discussão}

A partir dos resultados expostos constatei a produção de hortaliças no Sítio Logradouro em área contígua a cisterna calçadão. O produtor rural Davi Dantas juntamente com sua esposa, realiza essa produção durante o ano todo. Prepara o solo para o plantio adubando os canteiros com esterco bovino, adquiridos na própria propriedade, cuja característica do solo é neossolo regolítico.

A família trabalha em uma área com 12 hectares, sendo essa área inferior a 1 módulo fiscal, que para o município de Baraúna 1 módulo fiscal corresponde a 30 hectares e para ser considerado agricultor familiar pode possuir até 4 módulos fiscais.

Geralmente às espécies mais plantadas são o coentro, a alface muito sensível ao clima, o pimentão, a couve, a cebolinha, o tomate, a batata doce e a pimenta. Os canteiros após o plantio são irrigados duas vezes ao dia. O produtor não utiliza nenhum tipo de agrotóxico, fato pelo qual, o ambiente se encontra equilibrado e com diversidade de plantas. E para o controle de pragas no tomateiro o agricultor usa estratégias de proteção à planta simulando uma estufa individual confeccionada com materiais recicláveis.

Quanto à comercialização os produtos são vendidos, tanto aos consumidores, como aos atravessadores que comercializam nas feiras livres do município. Na Figura 2 podemos identificar algumas das práticas agroecológicas de controle de pragas e manejo do solo para os canteiros utilizadas pelo produtor rural familiar.

Figura 2 - Técnicas de controle de pragas no tomateiro (A) e esterco bovino amontoado para fermentação e posterior uso nos canteiros. Fonte: Própria. 

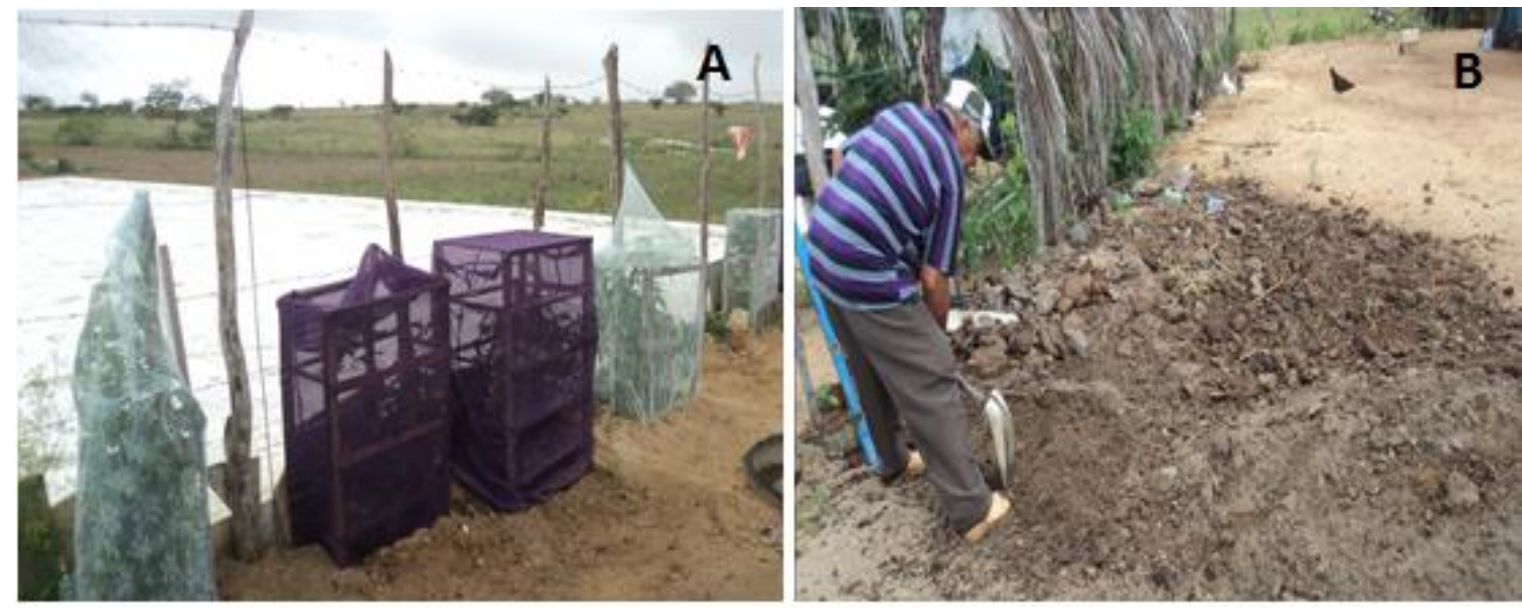

Segundo Aquino et al. (2005), não interessa qualquer tipo de diversidade, mas uma diversidade que proporcione uma série de serviços ecológicos, capazes de dispensar o uso de insumos. Essa diversidade deve incluir espécies fixadoras de nitrogênio, recicladoras de nutrientes, estimuladoras de predadores e parasitas de pragas, de polinizadores, estimuladoras de micorrizas, sideróforos, solubilizadores de fosfatos, etc. No caso da produção de hortaliças, conforme enuncia Filgueira (2003), esta deve se alicerçar na sustentabilidade, já que o seu objetivo primordial deve ser aprimorar a alimentação da família ou da comunidade. Dessa forma, busca-se a obtenção de hortaliças de alta qualidade, produzidas com requinte artesanal e em pequena escala.

Observou-se que dentre as plantas cultivadas no sistema de produção agroecológico da comunidade Logradouro, município de Baraúna, houve uma preferência pelo cultivo de hortaliças, frutíferas e plantas medicinais. Como também as culturas anuais de milho e feijão no período das águas. As hortaliças representam para a família uma segurança alimentar sendo comercializado o seu excedente.

Constatou-se uma grande variedade de espécies de plantas cultivadas, sendo a alface (Lactuca sativa) e o tomate (Solanum lycopersicum) as plantas mais cultivadas. De acordo com a visita na área do sistema agroecológico da família foi possível mapear 21 espécies vegetais. Dentre as as plantas medicinais, hortaliças e frutíferas cultivadas estão ilustradas na tabela 1 .

Tabela 1 - Espécies vegetais em um sistema de cultivo agroecológico contiguo a cisterna calçadão na comunidade Logradouro, Baraúna-PB. Fonte: Própria.

\begin{tabular}{lll} 
& Espécies vegetais do sistema produtivo \\
\hline Hortaliças & Medicinais & Frutíferas \\
\hline Coentro & Babosa & Banana \\
Couve & Capim santo & Caju
\end{tabular}




\begin{tabular}{lll} 
Cebolinha & Hortelã & Graviola \\
Alface & Mastruz & Mamão \\
Pimenta & Urtiga & Melancia \\
Batata doce & & Noni \\
Tomate & & Pinha \\
Pimentão & & Umbu \\
\hline
\end{tabular}

Total de espécies: 21

O sistema agroecológico da família de Davi Dantas, conta com uma grande diversidade de culturas, onde é retirada maior parte da alimentação da família. Segundo Siliprandi (2002), as evidências dos resultados da produção de alimentos de base agroecológica, são fruto dos novos métodos trabalhados com base nos princípios norteadores da agroecológica e tecnologias sociais de acesso á água, construída de forma participativa com os próprios agricultores/as, ONGs e algumas organizações locais. A autora ainda afirma que uma das vertentes mais relevantes da agroecologia afirma que a principal finalidade da estratégia utilizada encontra-se centrada na busca pela promoção da soberania e segurança alimentar e nutricional.

Além do cultivo de plantas foi constatado também a avicultura (galinhas, perus e guinés) e a apicultura (Figura 3). A avicultura é mantida principalmente para a alimentação da família, sendo raramente comercializado seus produtos (carne) e subprodutos (ovos), enquanto que a apicultura é mantida para subsistência e principalmente com fins comerciais. Existem no total 6 colméias de Apis mellifera pertencentes a esta família, porém devido a escassez de alimentos (floração) e água a quantidade de mel produzida não é constante, entretanto, segundo informações do Sr. Davi, os ninhos das abelhas italianas (A. mellifera) apresentam no total uma produção de 150 a 250 litros/ano, sendo vendidos a um custo de $\mathrm{R} \$$ 10,00/litro.

Pelo que expomos em relação à escassez de alimentos para as abelhas seria interessante à utilização da técnica da alimentação artificial, isso evitaria até mesmo que as colméias migrassem para outras áreas, evitando, desse modo a perda de alguma colméia.

Figura 3 - Integração do sistema de produção agroecológico: avicultura (A) e apicultura (B). Fonte: Própria. 

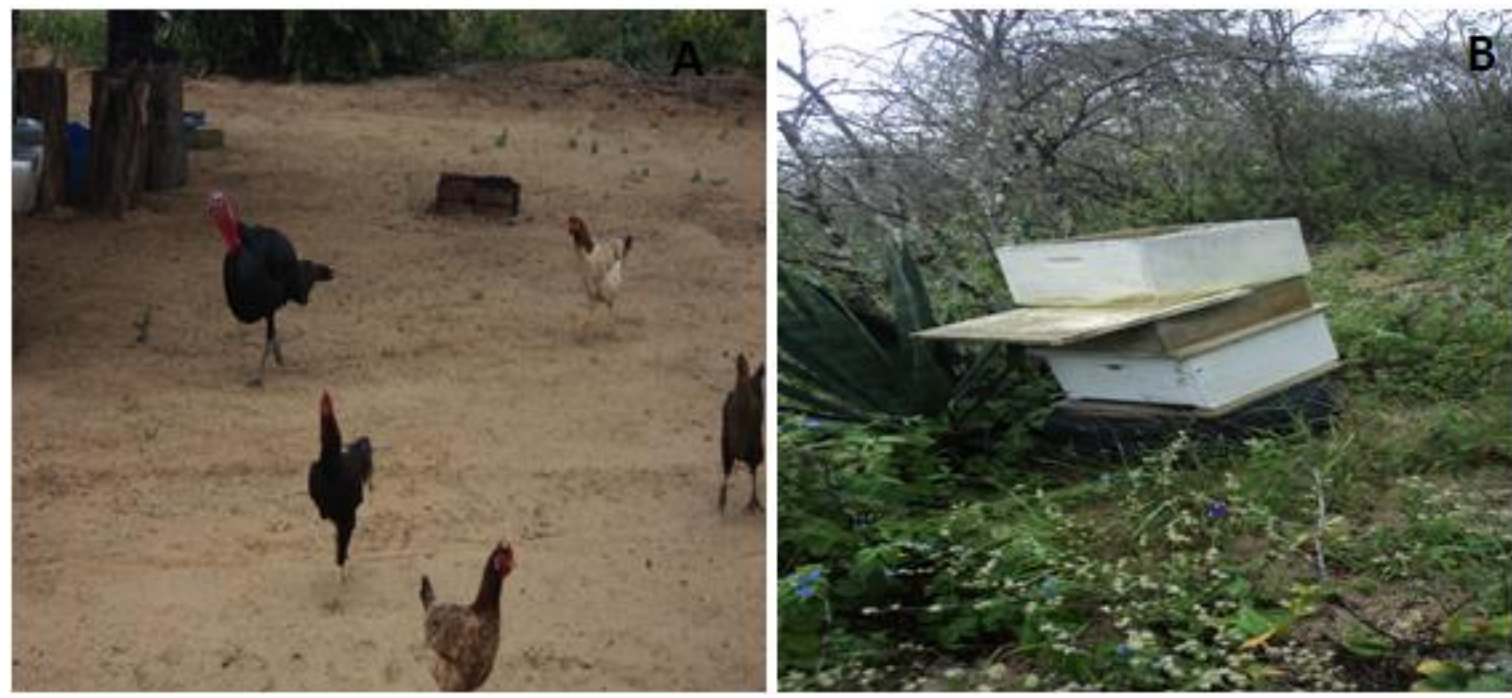

A criação de galinha de capoeira está presente na vida das famílias como estratégia clara de produção de alimentos, como também, uma alternativa de geração de renda. (MOURA et al., (2009). Esse tipo de ave criada à solta, exercitando-se e selecionando ao mesmo tempo o tipo de alimento, torna-se não imune mais tolerante a doenças. Nessas condições, são produzidas aves com melhor qualidade de carne e ovos, alimentos que, atualmente, são exigidos por uma sociedade de consumo mais consciente (SANTOS et al., 2009).

Em relação ao desenvolvimento da apicultura em regiões de semiárido, essa atividade está ganhando foco atualmente como uma das tecnologias sociais de convivência com a realidade semiárida, visto que a mesma trabalha com a interação dos parâmetros da sustentabilidade ambiental, social e econômica.

Para Cardoso (1999), a apicultura familiar é uma atividade integradora por excelência, pois complementa e beneficia as demais atividades da propriedade, aumentando a produção das culturas comerciais através da polinização e contribui para a diminuição da ocorrência do desmatamento e das queimadas na vegetação, matéria-prima da qual as abelhas dependem.

\section{Conclusões}

Conclui-se com este estudo de caso que a comunidade rural Logradouro atende aos parâmetros agroecológicos.

As atividades alternativas de sistemas produtivos praticadas para a subsistência familiar está voltado para a produção de hortaliças, plantas medicinais, frutíferas, avicultura e apicultura, com base no desenvolvimento rural sustentável.

As mudanças e inovações, com base nos princípios agroecológicos, praticadas contribuiu para viabilizar a preservação da biodiversidade existente. 
A unidade familiar recebeu o incentivo e apoio da ASA (Articulação no Semiárido Brasileiro).

\section{Agradecimentos}

Ao IFPB - Instituto Federal de Educação, Ciência e Tecnologia da Paraíba, Campus Picuí.

Ao NEA - Núcleo de Estudos em Agroecologia.

Ao GPES - Grupo Paraibano de Estudos Socioambientais.

\section{Referências}

AESA. Agência Executiva de Gestão das Águas do Estado da Paraíba, 2011. Disponível em: http://www.aesa.pb.gov.br/. Acesso em: 18 de set de 2016.

ALTIERI, M.; NICHOLLS, C. I. Agroecologia a dinâmica produtiva da agricultura sustentável. - 4. Ed. - Porto Alegre: Editora UFRS. 120 p. 2012.

AQUINO, A. M.; ASSIS, R. L. Agroecologia: princípios e técnicas para uma agricultura orgânica sustentável. Brasília-DF - EMBRAPA. 2005. 23, 67, 166, 276, 312, 325, 333 e 390 p.

BROOKFIELD, H. Exploring Agrodiversity. Columbia University Press, New York, USA. 608 p. 2007.

CAPORAL, F. R. Bases para uma Política Nacional de Formação de Extensionistas Rurais - Brasília: 55 p. 2009.

CARDOSO, I. R. Apicultura como estratégia de sobrevivência de unidades da agricultura familiar. Dissertação de Mestrado em Ciências Agrárias e Desenvolvimento Rural. Salvador: Escola de Agronomia da Universidade Federal da Bahia, 1999.

CARVAlHO, M. G. R. F. Estado da Paraíba: classificação geomorfológica. Editora Universitária/João Pessoa, 1992.

FILGUEIRA, F. A. R. Novo manual de olericultura:agrotecnologia moderna na produção e comercialização de hortaliças. $2^{\text {a }}$ Ed. Viçosa: UFV, 2003. Cap. 6, 20, 60 e 84 p.

HOLLING, C.S. Surprise for Science, Resilience for Ecosystems, and Incentives for People. Ecological Applications. v. 6, n. 3, p. 733-735. 2007.

IBGE. Instituto Brasileiro de Geografia e Estatística. Censo 2012.

KUSTER, A. et al. Agricultura Familiar, Agroecologia e Mercado. Agroecologia: plante esta idéia. Fortaleza: Fundação Konrad Adenauer, 2008. 
MOREIRA, R. N.; CARMO, M. S. Agroecologia na construção do desenvolvimento rural sustentável. In: Revista Agrícola de São Paulo, n.2, v.51. São Paulo (Brasil): 2004. p. 37-56.

MOURA, M. et al. Agroecologia e criação de galinhas de capoeira. Ouricuri: Caatinga. 2009. 5p.

MÜLLER, J. M; LOVATO, P. E; MUSSOI, E. M. Do tradicional ao agroecológico: as veredas das transições ( $O$ caso dos agricultores familiares de Santa Rosa de Lima/SC). Dissertação de Mestrado em Agroecossistemas. Florianópolis (Brasil): Universidade Federal de Santa Catarina, 2001.

NICHOLLS, C. I.; ALTIERI, M. Estratégias Agroecológicas para aumentar a resiliência nos contextos de mudanças climáticas. Mudanças Climáticas, Revista agricultores, vol. 1. 2012.

SANTOS, M. W. et al. Criação de galinhas caipira para produção de ovos em regime semi-intensivo. Programa Rio Rural. Manual técnico, 18. Niterói-RJ. 2009.

SILIPRANDI, E. Desafios para a extensão rural: o "social" na transição agroecológica. Rev. Agroecologia e Desenvolvimento Rural Sustentável, Porto Alegre, v.3, n.3, Jul/Set 2002.

TRIVINOS, A. N. S. Introdução à pesquisa em ciências sociais: a pesquisa qualitativa em educação. São Paulo (Brasil): Ed. Atlas, 1992.

VIERTLER R. B. Métodos Antropológicos como Ferramentas para Estudos em Etnobiologia e Etnoecologia. In: AMOROZO, M. C. M.; MING, L. C.; SILVA, S. P. (Eds.). Métodos de Coleta e Analise de Dados em Etnoecologia e Disciplinas Correlatas. Rio Claro (Brasil): UNESP/CNPq, 2002. 